\title{
Dynamic Failure Properties of the Porcine Medial Collateral Ligament- Bone Complex for Predicting Injury in Automotive Collisions
}

\author{
Louis Peck*,1, Kristen Billiar ${ }^{2}$ and Malcolm Ray ${ }^{3}$ \\ ${ }^{I}$ Mechanical Engineering, Worcester Polytechnic Institute, 100 Institute Road, Worcester, MA 01609, USA \\ ${ }^{2}$ Biomechanical Engineering, Worcester Polytechnic Institute, 100 Institute Road, Worcester, MA 01609, USA \\ ${ }^{3}$ Civil Engineering, Worcester Polytechnic Institute, 100 Institute Road, Worcester, MA 01609, USA
}

\begin{abstract}
The goal of this study was to model the dynamic failure properties of ligaments and their attachment sites to facilitate the development of more realistic dynamic finite element models of the human lower extremities for use in automotive collision simulations. Porcine medial collateral ligaments were chosen as a test model due to their similarities in size and geometry with human ligaments. Each porcine medial collateral ligament-bone complex $(\mathrm{n}=12)$ was held in a custom test fixture placed in a drop tower to apply an axial impulsive impact load, applying strain rates ranging from $0.005 \mathrm{~s}^{-1}$ to $145 \mathrm{~s}^{-1}$. The data from the impact tests were analyzed using nonlinear regression to construct model equations for predicting the failure load of ligament-bone complexes subjected to specific strain rates as calculated from finite element knee, thigh, and hip impact simulations. The majority of the ligaments tested failed by tibial avulsion (75\%) while the remaining ligaments failed via mid-substance tearing. The failure load ranged from $384 \mathrm{~N}$ to $1184 \mathrm{~N}$ and was found to increase with the applied strain rate and the product of ligament length and cross-sectional area. The findings of this study indicate the force required to rupture the porcine MCL increases with the applied bone-to-bone strain rate in the range expected from high speed frontal automotive collisions.
\end{abstract}

Keywords: Porcine, ligament, failure, injury, modeling, automotive, collision.

\section{INTRODUCTION}

Occupants involved in high speed frontal automotive collisions often experience knee, hip and thigh (KTH) injuries, which can result in long term or permanent disabilities with high associated societal costs. The cost of $\mathrm{KTH}$-related injuries caused by frontal automotive collisions is approximately four billion dollars per year [1]. To predict and ultimately prevent KTH injuries in high speed frontal automotive collisions, a more thorough understanding of the biomechanics and failure characteristics of the KTH and all of its components, including ligaments, is needed. For example, correctly predicting a hip dislocation or a fracture of the proximal femur depends largely on an accurate understanding of the ultimate strength of the surrounding ligaments. Further, to properly analyze the mechanics of ligamentous failure, the entire ligament-bone complex should be tested to determine the predominant failure location (e.g., midsubstance vs. enthesis). Additionally, the geometric properties of the components should be taken into account (e.g., aspect ratio).

Many studies have analyzed the effect of strain rate on the biomechanical properties of ligaments [2-9]. However, very few studies have examined the effect of high strain rates, such as those seen in high speed automotive collisions, on the failure properties of ligaments $[2,3,5,6]$, and even fewer have studied this effect as it relates to humans or large

*Address correspondence to this author at the Worcester Polytechnic Institute, 100 Institute Road, Worcester, MA 01609, USA;

Tel/Fax: 774.278.1449; E-mail: lpeck@sdlyons.com animals [5]. Consequently, there are very limited data regarding high speed ligamentous failure properties with respect to humans.

In the present study, porcine medial collateral ligamentbone complexes were subjected to strain rates up to $145 \mathrm{~s}^{-1}$ to determine the failure properties of ligaments and their attachment sites for use in computational models of human impact on the lower extremities. Improved knowledge of the relationships of the strength of ligament and attachment sites, anatomical features, and mechanical loading conditions will provide important data for simulating the failure mechanics of the KTH in collision environments. In short, an effective computational model would allow the analyst to predict the failure of human ligaments in automotive collisions. This, in turn, would allow the analyst to determine what solutions can be implemented to decrease the likelihood of failure, such as changes in automotive or roadside safety design.

Animal knees were used for testing in this study due to the difficulties of procuring human tissues in sufficient quantities. Further, porcine knees were selected because it has been shown that the porcine knee, when compared to other animals, is the best model for experimental studies to predict human behavior [10]. Specifically, the MCL was chosen because the ligament is relatively easily harvested. Moreover, the MCL was preferred to the LCL due to the size and geometry of the connected tibia, which facilitated gripping. Conversely, the LCL is connected to the fibula, which is much smaller and more fragile. 


\section{METHODS}

\subsection{Test Fixture}

To represent the conditions presented in high speed frontal automotive collisions as accurately as possible the porcine medial collateral ligament-bone complexes were subjected to impulsive impact loads. To isolate the longitudinal properties, the impact force placed on the ligament was oriented axially.

A custom testing fixture, for use with a Dynatup 8250 Drop Tower (Instron Corp., Norwood, MA), was designed to test the porcine ligaments. This drop tower has a maximum drop height of $1.2 \mathrm{~m}$ as well as a pneumatic assist option to achieve high velocity impacts. When a load is applied to the top disk of the fixture, as shown in Fig. (1), a tensile force of the same magnitude is transmitted to the specimen. The load was applied by impacting the top disk of the fixture with a 3.8 or $6.4 \mathrm{~kg}$ weight at a velocity between 1.8 and $7.6 \mathrm{~m} / \mathrm{s}$ depending on the desired applied strain rate. The larger weight was used for low impact velocities to ensure failure.

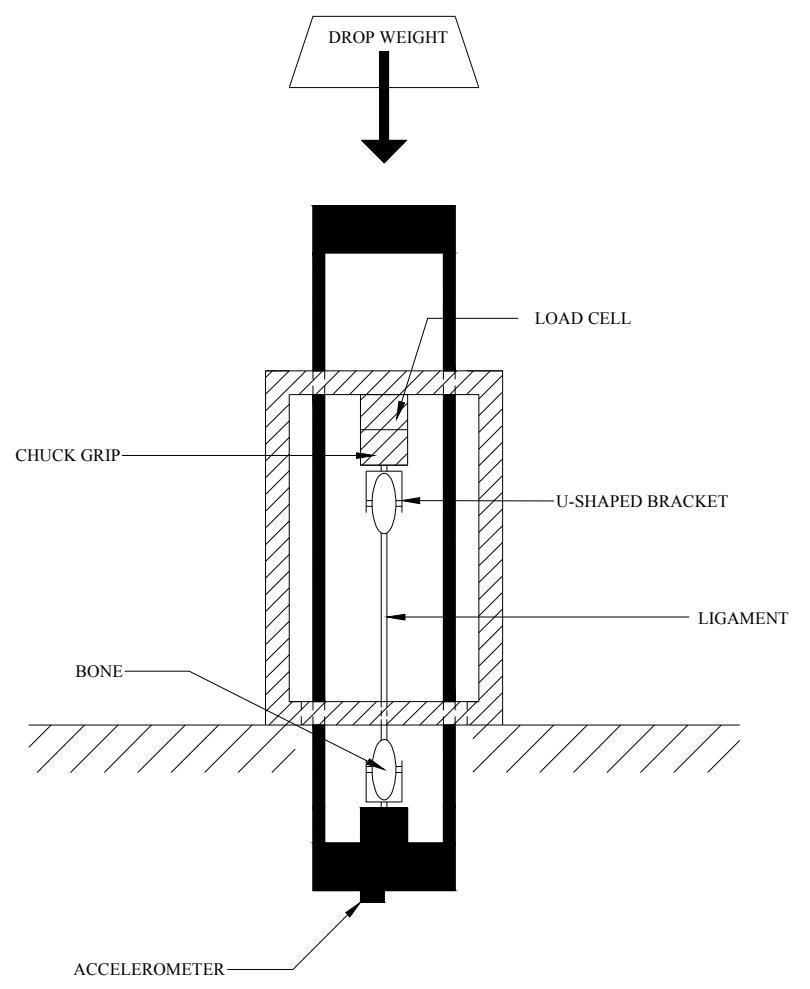

Fig. (1). Schematic showing the operation of the test fixture (moving parts shown in black). The three jaw keyless gripping chuck was threaded onto the load cell allowing a direct measure of the specimen axial force. The accelerometer was integrated into the fixture to enable the determination of the instantaneous grip-to-grip extension rates. Two bolts were inserted, transversely, through the femur and tibia. These bolts were secured to the chucks using the U-shaped bracket.

\subsection{Materials}

Eighteen mature porcine knees were obtained from two sources: a local slaughterhouse and the University of Massachusetts Medical School. Unfortunately, no data regarding the sex or age of the specimens were available. Both facilities treated the animals used for testing according to appropriate animal welfare regulations and guidelines. The knees were frozen the day of termination at $-20^{\circ}$ Celsius in Ziploc ${ }^{\circledR}$ Double Guard ${ }^{\circledR}$ (Johnson \& Son, Inc., Racine, WI) freezer bags with surrounding tissue intact. The knees were thawed the day of testing in a bath of water at room temperature and were tested within one month of initial storage. The mechanical properties of ligaments, when stored using a similar method, do not differ significantly from those of fresh samples [11].

\subsection{Mounting and Testing}

After thawing, the MCL was extracted for testing. The patella was removed and the knee was cut in half, longitudinally, using a pneumatic reciprocating saw. The meniscus and the fascia surrounding the ligament were then removed. Ligaments were frequently misted with saline solution $(0.9 \% \mathrm{NaCl})$ to maintain hydration during preparation. Two pilot holes were drilled for the gripping bolts in the femur and tibia. The holes were positioned to ensure the specimen was loaded axially to prevent undesirable tearing at the site of origin and insertion. The stress-free initial length of the ligament was measured using dial calipers with an accuracy of $25 \mu \mathrm{m}$. The ligament initial length was measured as the distance between the distal femoral attachment to the proximal tibial attachment.

After the gripping mechanisms were installed, the medial collateral ligament-bone complex was placed in a quasistatic tensile testing machine. A tare load of $20 \mathrm{~N}$ was placed on the ligament and the mid-substance dimensions were measured assuming a rectangular cross-section. Special care was taken when acquiring these measurements due to the viscoelastic nature of the specimen. The measurement was taken at the point when both surfaces of the calipers contacted the ligament without distorting it. All specimens were pre-conditioned to $7 \%$ of the initial stress-free, free length of the ligament at a rate of $0.25 \mathrm{~mm} / \mathrm{s}$ to simulate in vivo conditions.

Specimens were then installed into the impact test fixture. A high speed video system (i.e., Redlake PCI-8000S) was configured to record the test at 2000 frames per second and the load cell and accelerometer acquired the data at 25 $\mathrm{kHz}$. Based on information regarding the velocity of occupants in high speed frontal automotive collisions and common velocity changes for such collisions, the ligaments in this study were tested using extension rates ranging from $1.5 \mathrm{~m} / \mathrm{s}$ to $6.0 \mathrm{~m} / \mathrm{s}$ [12]. The extension rate was ranged by varying the impact velocity of the drop weight.

Three porcine knees received were unacceptable for impact testing. Two of the knees were too large to fit in the impact fixture and one was received with lacerated ligaments. Since the knees could not be used for impact testing, they were used to gather information regarding the geometry of the attachment sites. These knees were prepared in a similar manner as the knees described above. Before the gripping mechanism was attached, the cross-sectional dimensions, at the mid-substance, and the initial length of the ligament were recorded. The ligament was then torn from both the site of origin and insertion. At this point, the approximate area of the ligament attachment sites was 
measured using dial calipers. The mid-substance crosssectional dimensions of the ligament were then compared to the area of the attachment sites to determine if any relationship existed which may help understand the ligament failure mechanics.

\subsection{Instrument Validation}

Several tests were conducted to verify the data acquisition instrumentation. To verify the load cell, a number of masses were weighed using a calibrated scale. These masses were then weighed using the load cell and the results were compared. The weights spanned the loading range expected during live testing and the measurements were performed at the sampling frequency used during live testing to ensure validity. The average error was $0.6 \%$ and the values corresponded to the values on the calibration sheet provided by the load cell manufacturer.

The accelerometer was verified using two processes. The first process involved translating the acceleration measurements into information regarding the fixture's position using simple properties of linear dynamics, namely unidirectional double integration. Specifically, two measurements were taken on the fixture, the initial position and the position at which the moving parts of the fixture would reach a stopping point. This distance was then compared to the distance recorded by the accelerometer. The accelerometer data was also verified using the concepts of conservation of momentum. The mass of the moving parts of the fixture and the drop tower were determined and recorded. Using the hammer impact speed, which is recorded by the drop tower data acquisition system, and an approximate coefficient of restitution determined using high speed video, the theoretical post impact speed of the fixture's moving components was calculated. This number was compared to the value calculated using the acceleration data gathered from the accelerometer. The calculated values matched those given on the calibration sheet provided by the manufacturer.

\subsection{Analysis}

The point of failure was defined as the maximum force preceding any substantial decline in load. Using the information generated by the load cell and the accelerometer, the extension rate, load, and position at failure were identified and recorded. The extension rate at failure was divided by the initial free length of the ligament to obtain the strain rate at failure.

The data obtained during testing was analyzed using nonlinear regression and analysis of variance (ANOVA) in Mathematica 4.1. Numerous models were attempted in the pursuit of determining reliable predictors of the ligament failure load with independent variables including: the supplier of the porcine organ, the initial area of the ligament, the initial length of the ligament, the hammer impact velocity, and the strain rate of the ligament. Additionally, physically significant ratios of these variables, derived from variations of Hooke's Law, were analyzed. Reliable predictors were defined as having p-values less than 0.05 .

\section{RESULTS}

Three of the fifteen tests conducted were deemed unacceptable for analysis due to improper loading conditions or improper gripping conditions. Table $\mathbf{1}$ shows a summary of the results for the mechanical testing, and Table $\mathbf{2}$ shows a summary of the results for the geometric relationship between the initial ligament mid-substance cross sectional area and the initial area of the ligament-bone attachment sites, where any ligamentous material securely attached to the femur or tibia was measured.

\subsection{Mode of Failure}

As shown in Table 1, 75\% of the failures were categorized as tibial avulsions. This mode of failure involved the ligament tearing from the insertion site of the tibia and was further characterized by a layer of cortical bone, having an abrasive texture, attached to the avulsed end of the

Table 1. Summary of Results for Quasi-Static and Impact Testing of the Porcine Medial Collateral Ligament

\begin{tabular}{|c|c|c|c|c|c|c|c|c|}
\hline ID & $\mathbf{A}_{0}\left(\mathbf{m m}^{2}\right)$ & $\mathbf{L}_{0}(\mathbf{m m})$ & $\mathbf{V}_{\text {imp }}(\mathbf{m} / \mathbf{s})$ & $\varepsilon_{\text {failure }}(\%)$ & $\varepsilon_{\text {rate }}\left(\mathbf{s}^{-1}\right)$ & $\mathbf{P}_{\mathrm{F}}(\mathbf{N})$ & $\sigma_{\mathrm{F}}(\mathrm{MPa})$ & Failure Mode \\
\hline 1 & 6.10 & 36.96 & 2.27 & 31 & 63 & 521 & 86 & MS \\
\hline 3 & 6.74 & 38.39 & 4.67 & 27 & 138 & 600 & 89 & MS \\
\hline 4 & 7.84 & 39.32 & 1.93 & 21 & 56 & 401 & 51 & TA \\
\hline 6 & 8.12 & 34.67 & 2.91 & 17 & 97 & 384 & 47 & TA \\
\hline 7 & 11.21 & 36.73 & 3.83 & 30 & 119 & 786 & 70 & TA \\
\hline 8 & 11.90 & 31.00 & 4.01 & 37 & 140 & 844 & 71 & TA \\
\hline 12 & 42.57 & 50.93 & N/A & 69 & QS & 2836 & 67 & MS \\
\hline
\end{tabular}


Table 2. Relationships Between Ligament Mid-Substance Geometry and Origin and Insertion Site Geometry

\begin{tabular}{|c|c|c|c|c|}
\hline Ligament & $\mathbf{A}_{\mathbf{0}}\left(\mathbf{m m}^{2}\right)$ & $\mathbf{L}_{\mathbf{0}}(\mathbf{m m})$ & Origin $\mathbf{A}_{\mathbf{0}}\left(\mathbf{m m}^{2}\right)$ & Insertion $\mathbf{A}_{\mathbf{0}}\left(\mathbf{m m} \mathbf{m}^{\mathbf{2}}\right)$ \\
\hline \hline MCL & 9.21 & 44.73 & 1464.38 & 629.03 \\
\hline MCL & 27.34 & 43.43 & 2851.61 & 585.48 \\
\hline MCL & 27.76 & 39.62 & 2235.48 & 774.19 \\
\hline
\end{tabular}

ligament [6]. These failures generally involved the detachment of a portion of the muscle surrounding the insertion site as well.

While the majority of ligaments failed via tibial avulsion, a significant portion of the failures $(25 \%)$ were defined as mid-substance failure. During this type of failure the ligament tore near the mid-substance of the ligament, while the origin and insertion sites appeared to be undamaged. These failures were seen over the entire range of strain rates tested.

\subsection{Biomechanical Behavior}

The loading rate had a pronounced effect on the failure load, which ranged from 384 to $2836 \mathrm{~N}$, but seemed to have no effect on the failure stress, which ranged from 40 to 86 $\mathrm{MPa}$, (see Figs. 2 and 3). It is important to note that the failure stress is defined as the failure load over the crosssectional area in the center of the ligament, which is not where the majority of the failures occurred. The relationship between loading rate and failure stress is discussed in greater detail in Section 4. As expected, the relationship between the failure load and the failure strain was largely linear, (see Fig. 4).

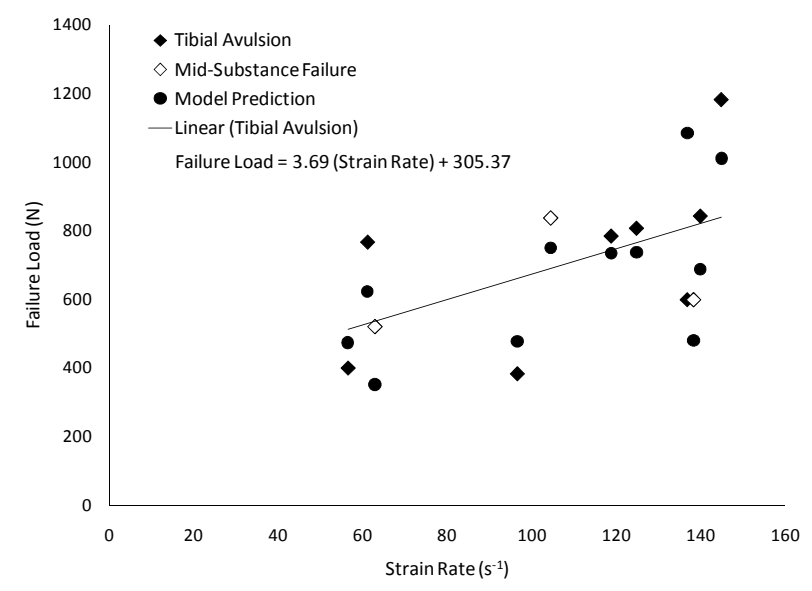

Fig. (2). Failure load versus strain rate for 11 porcine MCL ligament-bone specimens with a regression line of all high speed experimental data. Notice, the mid-substance failure data fits very well with the tibial avulsion data.

\subsection{Statistical Analysis}

The statistical analyses revealed three reliable predictors of the failure load, namely: the initial cross sectional area, the initial length, and the applied strain rate. The best combination of these predictors was identified to establish the failure load model. The best model fit was defined as the model with: the lowest predictor variable p-values $(<0.05)$, the highest $\mathrm{R}^{2}$ value, and the greatest physical significance. The resulting model equation is shown below:

$P=a * A_{\mathrm{o}} * L(1+b *$ strain rate $)$

Where: $A_{o}$ is the initial cross sectional area $\left(\mathrm{mm}^{2}\right), \mathrm{L}$ is the initial length $(\mathrm{mm})$, strain rate is the applied strain rate at failure $\left(\mathrm{s}^{-1}\right)$ and $a$ and $b$ are constants, specifically 1.32 $\mathrm{N} / \mathrm{mm}^{3}$ and $0.003 \mathrm{~s}$, respectively. The statistical model is composed of two terms: the first term, composed of geometric parameters, describes the quasi-static failure load,

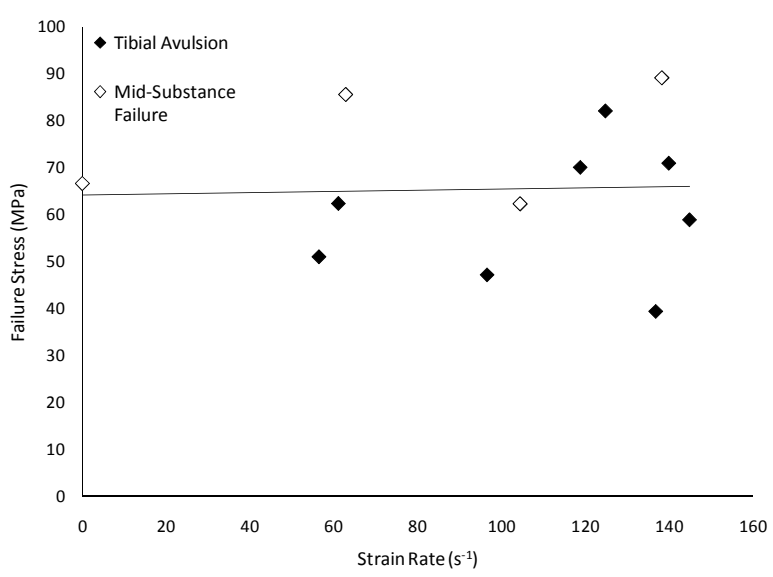

Fig. (3). Failure stress versus strain rate for 12 porcine MCL ligament-bone specimens with regression line.

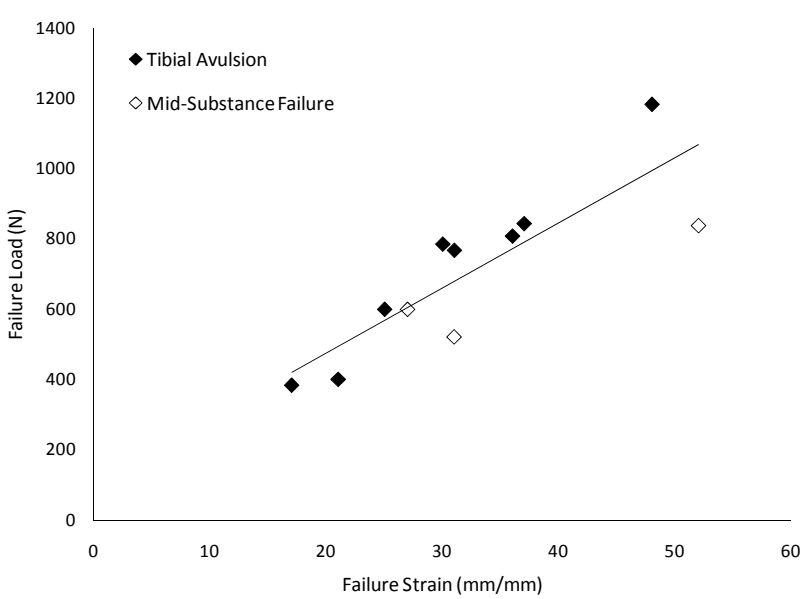

Fig. (4). Failure load versus failure strain for 11 dynamic porcine MCL ligament-bone tests including regression line. 
Table 3. Summary of Statistical Analysis Showing Prospective Failure Load Models and their Respective $\mathbf{p}$ and $\mathbf{R}^{2}$ Values

\begin{tabular}{|c|c|c|c|c|c|c|c|c|}
\hline ID & $\mathbf{X}_{1}$ & $\mathbf{X}_{2}$ & $\mathbf{X}_{3}$ & $\mathbf{Y}$ & $P_{1}$ Value & $P_{2}$ Value & $P_{3}$ Value & $\mathbf{R}^{2}$ \\
\hline 1 & $A_{o}$ & & & $\mathrm{P}_{\mathrm{F}}$ & 0.0001 & & & 0.96 \\
\hline 2 & $\varepsilon_{\text {rate }}$ & & & $\mathrm{P}_{\mathrm{F}}$ & 0.0001 & & & 0.92 \\
\hline 3 & $\mathrm{~W}_{\mathrm{o}}$ & & & $\mathrm{P}_{\mathrm{F}}$ & $<0.0001$ & & & 0.95 \\
\hline 4 & $\mathrm{Th}_{\mathrm{o}}$ & & & $\mathrm{P}_{\mathrm{F}}$ & $<0.0001$ & & & 0.90 \\
\hline 5 & $\mathrm{~L}_{\mathrm{o}}$ & & & $\mathrm{P}_{\mathrm{F}}$ & $<0.0001$ & & & 0.86 \\
\hline 6 & $\mathrm{~A}_{\mathrm{o}} / \mathrm{L}_{\mathrm{o}}$ & & & $\mathrm{P}_{\mathrm{F}}$ & $<0.0001$ & & & 0.94 \\
\hline 7 & $\mathrm{~L}_{\mathrm{o}} / \mathrm{A}_{\mathrm{o}}$ & & & $\mathrm{P}_{\mathrm{F}}$ & 0.0016 & & & 0.65 \\
\hline 8 & $\varepsilon_{\text {rate }}$ & & & $\mathrm{P}_{\mathrm{F}}$ & $<0.0001$ & & & 0.92 \\
\hline 9 & $\varepsilon_{\text {failure }}$ & & & $\mathrm{P}_{\mathrm{F}}$ & $<0.0001$ & & & 0.97 \\
\hline 10 & $\varepsilon_{\text {rate }}^{2}$ & & & $\mathrm{P}_{\mathrm{F}}$ & $<0.001$ & & & 0.85 \\
\hline 11 & $\varepsilon_{\text {rate }}$ & $\mathrm{L}_{\mathrm{o}} / \mathrm{A}_{\mathrm{o}}$ & & $\mathrm{P}_{\mathrm{F}}$ & 0.0003 & 0.8885 & & 0.92 \\
\hline 12 & $\varepsilon_{\text {rate }}$ & $\mathrm{A}_{\mathrm{o}} / \mathrm{L}_{\mathrm{o}}$ & & $\mathrm{P}_{\mathrm{F}}$ & 0.0127 & 0.0051 & & 0.97 \\
\hline 13 & $\varepsilon_{\text {rate }}$ & $\mathrm{Th}_{\mathrm{o}}$ & & $\mathrm{P}_{\mathrm{F}}$ & 0.0511 & 0.1649 & & 0.94 \\
\hline 14 & $\varepsilon_{\text {rate }}$ & $\mathrm{W}_{\mathrm{o}}$ & & $\mathrm{P}_{\mathrm{F}}$ & 0.1329 & 0.0185 & & 0.96 \\
\hline 15 & $\varepsilon_{\text {rate }}$ & $A_{o}$ & & $\mathrm{P}_{\mathrm{F}}$ & 0.1397 & 0.0064 & & 0.97 \\
\hline 16 & $\varepsilon_{\text {rate }}$ & $\mathrm{L}_{\mathrm{o}}$ & & $\mathrm{P}_{\mathrm{F}}$ & 0.0178 & 0.5708 & & 0.92 \\
\hline 17 & $\varepsilon_{\text {rate }}^{2}$ & $\mathrm{~A}_{\mathrm{o}} / \mathrm{L}_{\mathrm{o}}$ & & $\mathrm{P}_{\mathrm{F}}$ & 0.0968 & 0.0018 & & 0.95 \\
\hline 18 & $\varepsilon_{\text {rate }}$ & $\mathrm{L}_{\mathrm{o}} / \mathrm{A}_{\mathrm{o}}$ & $\mathrm{A}_{\mathrm{o}}$ & $\mathrm{P}_{\mathrm{F}}$ & 0.4072 & 0.5439 & 0.0085 & 0.97 \\
\hline 19 & $\varepsilon_{\text {rate }}$ & $\mathrm{L}_{\mathrm{o}}$ & $\mathrm{A}_{\mathrm{o}}$ & $\mathrm{P}_{\mathrm{F}}$ & 0.3598 & 0.6994 & 0.0112 & 0.97 \\
\hline 20 & $\varepsilon_{\text {rate }}$ & $\mathrm{A}_{\mathrm{o}} / \mathrm{L}_{\mathrm{o}}$ & Supplier & $\mathrm{P}_{\mathrm{F}}$ & 0.3772 & 0.0132 & 0.4458 & 0.98 \\
\hline 21 & $\varepsilon_{\text {rate }}$ & $\mathrm{A}_{\mathrm{o}} / \mathrm{L}_{\mathrm{o}}$ & $F_{\text {imp }}$ & $\mathrm{P}_{\mathrm{F}}$ & 0.8204 & 0.0168 & 0.2961 & 0.97 \\
\hline 22 & $\varepsilon_{\text {rate }}$ & $\mathrm{A}_{0} / \mathrm{L}_{\mathrm{o}}$ & $\mathrm{V}_{\text {imp }}$ & $\mathrm{P}_{\mathrm{F}}$ & 0.5289 & 0.3245 & 0.1883 & 0.95 \\
\hline
\end{tabular}

whereas the second term accounts for the strain rate effect. The $\mathrm{p}$-value of the first term was $<0.001$ while the $\mathrm{p}$-value of the strain rate term was 0.03 . The $\mathrm{R}^{2}$ value of the model was 0.92 and the root mean squared error was $190 \mathrm{~N}$. A summary of all other prospective models, including their corresponding $\mathrm{p}$-values and $\mathrm{R}^{2}$ values are shown in Table $\mathbf{3}$.

\section{DISCUSSION}

\subsection{Biomechanics}

The findings of this study demonstrate the force required to rupture the porcine MCL increases with the applied boneto-bone strain rate in the range expected from high speed frontal automotive collisions. From Eq. (1), it can be seen that there is over a $40 \%$ change when comparing the quasistatic failure load to the failure load at a strain rate of $140 \mathrm{~s}^{-1}$, clearly demonstrating the substantial rate effect. Further, we found that information regarding the initial length and crosssectional area are significant indicators of ligament failure load even though the majority of ligament-bone complexes failed at the attachment site. Specifically, the model indicates failure load will increase as the cross-sectional area of the ligament increases. This relationship is expected for mid- substance failures, but intuitively less pertinent to tibial avulsions. However, as shown above, limited data indicates the insertion and origin attachment area increased as the midsubstance area of the ligament increased. This increase in attachment site area would logically increase the tibial avulsion failure load.

The model indicates the failure load will increase as the ligament initial length increases. Further research is required to develop a theory for this behavior. However, one explanation may be derived from the organization of the collagen fibers comprising the ligament, which are known to be responsible for the high tensile strength of ligaments [13]. Collagen fibers are believed to be organized in bundles and oriented along the principle stress axis of the ligament. Therefore, depending on the geometry of the joint and ligament configuration, it is likely that not all collagen bundles are strictly parallel [13]. Taken these facts into consideration, it is possible long and skinny ligaments may have highly organized and longitudinally oriented collagen fibers near the mid-substance due to the fact that the ligament is not required to provide support in any other direction at that location. On the contrary, the collagen fibers 
near the mid-substance of short and wide ligaments may be responsible for supporting loads in directions other than longitudinally, as a result of being closer to the origin and insertion site. Consequently, long and skinny ligaments may possess higher axial strength, which would describe the relationship between failure load and the ligament length.

Since the data from this study are being used to develop a model to predict the failure of ligament-bone complexes, the location of the failure (mid-substance versus attachment site) does not affect the main results of force at failure. Consequently, the data from both types of failure were analyzed collectively. Additionally, due to the fact that we were attempting to acquire information useful for computational finite element models, the strain rate effect on the mid-substance of the ligament was not our main concern. Instead, the relative dynamic motion of the ligament attachment sites is more useful in finite element models and was quantified using the bone-to-bone (grip-to-grip) strain rate in this study. Although the results from grip-to-grip strain rate measurements and mid-substance strain rate methods may be quantitatively different, comparing the trends in results is beneficial.

Data presented in similar studies agree with the data presented herein. Specifically, France, et al. [5], performed a study on 12 Human MCLs to determine the effect of strain rate on ligamentous failure load. The author tested six knees at a strain rate of $1 \mathrm{~s}^{-1}$ and six knees at $10 \mathrm{~s}^{-1}$ and found the failure load is approximately $28 \%$ higher in the group subjected to high strain rate. Similarly, Lydon et al. [6], when testing the anterior cruciate ligament of rabbits at strain rates of approximately $0.005 \mathrm{~s}^{-1}$ and $50 \mathrm{~s}^{-1}$, found failure load increases from the slow to the fast group by $74 \%$.

Likewise, authors have studied the effect of applied strain rate with respect to the failure stress of ligaments. When examining the data from the current study, no obvious relationship between the applied strain rate and the failure stress exists, (see Fig. 3). However, when other parameters, such as initial length, are included in the model, a relationship becomes more evident. Rearranging the model equation to solve for failure stress, it is seen that the failure load, and consequently the failure stress, are related to the initial length of the ligament and increase with the applied strain rate. Crowninshield and Pope [3] tested the MCL of rats quasi-statically and at a strain rate of $190 \mathrm{~s}^{-1}$ and found the failure stress significantly increased with the applied strain rate. Crisco, et al. [2], studied the rabbit MCL and found a significant difference in ligamentous strength between quasi-static loading and impact loading, but found no significant difference when comparing the ultimate strength of groups tested at strain rates of $50 \mathrm{~s}^{-1}$ and $200 \mathrm{~s}^{-1}$. This discrepancy could be due to the fact that ligamentous viscosity can differ between species, resulting in a different strain rate effect. However, it is also possible that ligament viscosity does not relate to failure stress or failure load since the collagen strength, as well as the ligament-bone integration strength, are likely independent of ligamentous viscosity.

It is important to note that failure stress was not the salient metric in this study since the nominal stress was calculated at the mid-substance and the majority of failures were at the insertion site. Therefore, the actual stress at which the ligament fails was not known and should not be the parameter modeled. However, the ligamentous cross sectional area relates to the geometric conditions present at the sites of origin and insertion. Ligaments with larger cross sectional areas tended to have larger areas of origin, as seen in Table 2, and were therefore naturally stronger at this attachment site. The same relationship may also be valid for the site of insertion; however, sufficient data were not gathered to validate this theory.

\subsection{Mode of Failure}

While there was no significant rate effect on the mode of failure in this study, other researchers have found the applied strain rate affects the mode of failure. Lydon et al. [6], found significantly more mid-substance failures occurred at a strain rate of $50 \mathrm{~s}^{-1}$ when compared to $0.005 \mathrm{~s}^{-1}$. However, as found in this study, the authors report that the majority of ligaments failed by avulsion [6]. Crowninshield and Pope [3] also found a greater proportion of mid-substance failures at high strain rates $\left(190 \mathrm{~s}^{-1}\right)$ when compared to low strain rates (quasi-static). Peterson et al. [7], observed that the percentage of failure via tibial avulsion increases as the applied strain rate increases.

The results of the mid-substance failures agree very well with the data from the tibial avulsions, which indicates that the strength of the tibial attachment site is similar, but slightly weaker, than the strength of the mid-substance. Further, every avulsion failure occurred at the tibial attachment site, indicating the ligament-bone attachment at the tibia was weaker than the ligament-bone attachment at the femur. This finding is likely due to the fact that the area of the tibial attachment is smaller than the area of the femoral attachment and consequently requires less force to cause avulsion (Table $\mathbf{2}$ ).

\subsection{Failure Strain}

The failure strain of the MCLs tested in this study spanned a great range, specifically 17 to $69 \%$, while the average failure strain was approximately $35 \%$. The average strain rate seen in this study agrees with the failure strains calculated from the displacements reported by Crisco et al. [2]. These failure strain values differ greatly from those reported by Martin et al. [13], who indicate that the failure strain of ligaments is typically between 12 and $18 \%$. However, this latter study did not utilize high strain rates as produced in this study as well as the study of Cisco et al. [2].

The greatest failure strain was observed in the quasistatic test where the failure load exceeded $2800 \mathrm{~N}$, which is more than twice the maximum failure load observed in the remaining 11 tests. This uncharacteristically large load was due to the fact that the specimen was significantly larger than the other involved specimens. This sizeable loading may have distorted the ligament mounting brackets or lead to slipping of the tissue, which would account for the unusually high failure strain.

\subsection{Statistical Model}

The terms in the model presented herein were chosen based on statistical and physical reasoning. Statistical analysis showed the initial cross sectional area and length of 
the ligament were strongly correlated to the failure load and were therefore included in this model. These terms, however, were also included due to the fact that they relate to the insertion and origin site geometry. The second term of Eq. (1) was included to account for the strain rate effect and defaults to unity when the strain rate is zero.

Failure strain was excluded from the model because the relationship between failure load and failure strain was found to be linear. Therefore, it was concluded that transforming strains to stress and then failure load was a simple linear mapping. In other words, the ultimate load, the failure strain, and the failure stress all contain the same statistical information such that knowing one allows the others to be calculated using the usual definitions of stress, strain and load. The variables that best model ligamentous failure were found to be the ligament cross-sectional area, initial length and strain rate.

\subsection{Method Limitations}

In order to accurately determine the failure characteristics of the MCL, the entire medial collateral ligament-bone complex was extracted and tested to ensure the ligament attachment sites were included in the study and also to minimize problems associated with directly gripping ligaments. The ligament cross-sectional area was assumed to be rectangular to simplify measurements and calculations. When analyzing the data presented, it is important to note that the cross-sectional measurements were taken at the midsubstance of the ligament.

A limitation of this study was the inability to measure the free length of the ligament under tare loading. Optimally, this dimension would have been recorded once the tare load was applied to the specimen. However, gripping conditions prevented any accurate measurement of the ligament length with the tare-load applied so the measurement had to be taken before the grips were installed. Using ligamentous stiffness data and the average length and cross-sectional area of the ligaments tested, it was determined that the error caused by this procedural necessity is insignificant (less than $0.03 \%)$.

Measurement of the ligament attachment sites was difficult without advanced equipment. In this study the attachment site was approximated and measured using dial calipers. This rough estimation method was used to determine if there was a strong relationship between the area of the attachment site and the mid-substance cross sectional area of a ligament. A precise quantitative analysis could be performed using contrast magnetic resonance arthography [14].

\subsection{Extending Porcine MCL Results}

Since the model presented herein considers the geometric properties of the ligament, it may possible to use the model equation to predict the failure load of the MCL as well as other ligaments. However, this would assume other ligamentous materials have similar relationships between the ligament and insertion sites. Further testing would be required to substantiate or disprove the predictive capabilities of the model developed in this study. This model has the potential to give the analyst a simple tool to analyze ligament failure at specific strain rates using only two geometric parameters.

\section{ACKNOWLEDGEMENTS}

The authors would like to thank the University of Massachusetts Medical School for supplying the tissues necessary to conduct this research. This work was supported by the National Highway Traffic Safety Administration Contract DTNH22-04-H-01424, "Analytical Crash Simulation".

\section{NOMENCLATURE}

$\begin{array}{ll}\mathrm{a} & =\text { Constant }\left(1.32 \mathrm{~N} / \mathrm{mm}^{3}\right) \\ \mathrm{b} & =\text { Constant }(0.003 \mathrm{~s}) \\ \mathrm{A}_{\mathrm{o}} & =\text { Initial cross-sectional area } \\ \mathrm{F}_{\mathrm{imp}} & =\text { Drop tower hammer impact force } \\ \mathrm{L}_{\mathrm{o}} & =\text { Initial length } \\ \mathrm{P}_{\mathrm{F}} & =\text { Failure load } \\ \mathrm{Th}_{\mathrm{o}} & =\text { Initial cross-sectional thickness } \\ \mathrm{V}_{\mathrm{imp}} & =\text { Drop tower hammer impact velocity } \\ \mathrm{W}_{\mathrm{o}} & =\text { Initial cross-sectional width } \\ \varepsilon_{\text {failure }} & =\text { Strain at failure } \\ \varepsilon_{\text {rate }} & =\text { Strain rate at failure } \\ \sigma_{\mathrm{F}} & =\text { Failure stress }\end{array}$

\section{REFERENCES}

[1] S. Kuppa, "An overview of knee-hip-thigh injuries in frontal crashes in the united states," NHTSA Paper No. 416, 2003.

[2] J. Crisco, D. Moore and Rd. Mcgovern, "Strain-rate sensitivity of the rabbit MCL diminishes at traumatic loading rates," J. Biomech., vol. 35, pp. 1379-1385, 2003.

[3] R. Crowninshield and M.H. Pope, "The strength and failure characteristics of the rat medial collateral ligament," J. Trauma, vol. 16, pp. 99-105, 1976.

[4] M. Danto and S.L.-Y. Woo, "The mechanical properties of skeletally mature rabbit anterior cruciate ligament and patellar tendon over a range of strain rates," J. Orthop. Res., vol. 11, pp. 5867, 1993.

[5] E. France, L. Paulos, P. Abbott, et al., "Failure characteristics of the medial collateral ligament of the knee: Effect of high strain rate," Aviat. Space Environ. Med., vol. 588, pp. 488, 1987.

[6] C. Lydon, J.J. Crisco, M. Panjabi and M. Galloway, "Effect of elongation rate on the failure properties of the rabbit anterior cruciate ligament," Clin. Biomech., vol. 10, pp. 428-433, 1995.

[7] R. Peterson and S.L-Y. Woo, "A new methodology to determine the mechanical properties of ligaments at high strain rates," $J$. Biomech. Eng., vol. 108, pp. 365-367, 1986.

[8] S.L.-Y. Woo, "The time and history-dependent viscoelastic properties of the canine medial collateral ligament," J. Biomech. Eng., vol. 103, pp. 293-298, 1981.

[9] S.L.-Y. Woo, R.H. Peterson, K.J. Ohland, T.J. Sites and M.I Danto, "The effects of strain rate on the properties of the medial collateral ligament in skeletally immature and mature rabbits: A biomechanical and histological study," J. Orthop. Res., vol. 8, pp. 712-721, 1990.

[10] J.W. Xerogeanes, R.J. Fox, Y. Takeda, H-S. Kim, Y. Ishibashi, G.J. Carlin and S.L-Y. Woo, "A functional comparison of animal anterior cruciate ligament models to the human anterior cruciate ligament," Ann. Biomed. Eng., vol. 26, pp. 345-352, 1998.

[11] S.L.-Y. Woo, "Effects of postmortem storage by freezing in ligament tensile behavior," J. Biomech., vol. 19, pp. 399-404, 1986.

[12] M. Araszewski and A. Toor, "Head, hip and knee velocities of restrained occupants in frontal impacts," Accident Reconstruction, 2003-01-0884, 2003. 
[13] R. Martin, D. Burr, N.A. Sharkey, Skeletal tissue mechanics, Springer: New York, 1998.
[14] H. Stäubli, W. Rauschning, "Tibial attachment area of the anterior cruciate ligament in the extended knee position," Knee Surg. Sports Traumatol. Arthrosc., vol. 2, pp. 138-146, 1994.

Received: November 18, 2009

Revised: February 21, 2010

Accepted: February 23, 2010

(C) Peck et al.; Licensee Bentham Open.

This is an open access article licensed under the terms of the Creative Commons Attribution Non-Commercial License (http://creativecommons.org/licenses/by-nc/3.0/) which permits unrestricted, non-commercial use, distribution and reproduction in any medium, provided the work is properly cited. 